\title{
Highly Selective and Rapid Breath Isoprene Sensing Enabled by Activated Alumina Filter
}

\section{Journal Article}

\section{Author(s):}

van den Broek, Jan; Güntner, Andreas (i); Pratsinis, Sotiris E.

Publication date:

2018-03-23

Permanent link:

https://doi.org/10.3929/ethz-b-000242679

Rights / license:

In Copyright - Non-Commercial Use Permitted

Originally published in:

ACS Sensors 3(3), https://doi.org/10.1021/acssensors.7b00976

\section{Funding acknowledgement:}

159763 - Nanostructured metal-oxide gas sensors for non-invasive disease detection by breath analysis (SNF) 170729 - Integrated system for in operando characterization and development of portable breath analyzers (SNF) 


\title{
Highly Selective and Rapid Breath Isoprene Sensing Enabled by Activated Alumina Filter
}

\author{
Jan van den Broek, Andreas T. Güntner* and Sotiris E. Pratsinis \\ Particle Technology Laboratory, Department of Mechanical and Process Engineering, \\ ETH Zurich, CH-8092 Zurich, Switzerland
}

*corresponding author: andreas.guentner@ptl.mavt.ethz.ch 


\section{Abstract}

Isoprene is a versatile breath marker for non-invasive monitoring of high blood cholesterol levels as well as for influenza, end-stage renal disease, muscle activity, lung cancer and liver disease with advanced fibrosis. Its selective detection in complex human breath by portable devices (e.g. metal-oxide gas sensors), however, is still challenging. Here, we present a new filter concept based on activated alumina powder enabling fast and highly selective detection of isoprene at the ppb level and high humidity. The filter contains high surface area adsorbents that retain hydrophilic compounds (e.g. ketones, alcohols, ammonia) representing major interferants in breath while hydrophobic isoprene is not affected. As a proof-ofconcept, filters of commercial activated alumina powder are combined with highly sensitive but rather non-specific, nanostructured Pt-doped $\mathrm{SnO}_{2}$ sensors. This results in fast (10 s) measurement of isoprene down to $5 \mathrm{ppb}$ at $90 \%$ relative humidity with outstanding selectivity (>100) to breath-relevant acetone, ammonia, ethanol and methanol, superior to state-of-theart isoprene sensors. Most importantly, when exposed continuously to simulated breath mixtures (four analytes) for eight days, this filter-sensor system showed stable performance. It can be incorporated readily into a portable breath isoprene analyzer promising for simplein-use blood cholesterol monitoring or other patho/physiological conditions.

\section{Keywords:}

isoprene, cholesterol, activated alumina, filter, adsorption, breath analysis, $\mathrm{SnO}_{2}$, flame spray pyrolysis 
Cardiovascular diseases are the leading cause of death, ${ }^{1}$ accounting for more than $30 \%$ of global deaths in $2015 .^{2}$ Most of them could be preventable by reducing the major risk factors, including smoking, high blood pressure and high blood cholesterol. ${ }^{3}$ Currently, cholesterol is measured from a lipid profile obtained by a blood test. This means $9-12$ hours of fasting before going to a physician for the measurement, ${ }^{4}$ which is both painful and elaborate, especially as often follow-up analyses are necessary due to large day-to-day variation in blood cholesterol concentrations. ${ }^{5}$ What is thus needed, is a fast and non-invasive method to reliably and routinely monitor blood cholesterol levels at home.

Breath analysis is a non-invasive diagnostic and monitoring technique that relies on detection of certain breath markers indicative of pathologic states. ${ }^{6}$ Exhaled isoprene is a byproduct of the cholesterol biosynthetic pathway ${ }^{7}$ with typical breath concentrations ranging from 22 to 234 parts-per-billion (ppb) ${ }^{8}$ but even lower levels can occur in children ${ }^{9}$ and young adults. ${ }^{10}$ Most interestingly, a strong correlation between breath isoprene and blood cholesterol was shown for patients undergoing treatment with cholesterol-lowering lova- ${ }^{11}$ and atorvastatins. ${ }^{12}$ Increased breath isoprene levels occur also in patients with influenza, ${ }^{13}$ end-stage renal disease ${ }^{14}$ and after muscle activity, ${ }^{15}$ while such levels are decreased for lung cancer ${ }^{16}$ and liver disease with advanced fibrosis. ${ }^{17}$ Currently, breath isoprene is detected by mass spectrometry-(MS) ${ }^{11}$ or gas chromatography- $(\mathrm{GC})^{18}$ that are rather expensive, of limited portability and require scientific personnel to operate. Chemiluminescence measurement of isoprene is also possible but shows high interference from sulfur gases and other lower olefins, making precise measurement inaccurate. ${ }^{19}$ As a result, available methods are hardly suitable for routine breath tests.

Isoprene $\left(\mathrm{CH}_{2}=\mathrm{C}\left(\mathrm{CH}_{3}\right)-\mathrm{CH}=\mathrm{CH}_{2}\right)$ is a reactive, aliphatic hydrocarbon ${ }^{20}$ that can be detected at low ppb concentrations also by nanostructured semiconductive metal-oxide (MOx) gas sensors. In specific, sensing films of Ti-doped $\mathrm{ZnO}$ deposited by flame aerosol 
technology were shown to detect isoprene levels down to $5 \mathrm{ppb}$ at breath-relevant $90 \%$ relative humidity. ${ }^{21}$ Such sensors are attractive for breath analysis by being inexpensive, simple-in-use and readily miniaturized ${ }^{22}$ and integrated into portable devices. ${ }^{23}$ They also have been applied already quite successfully for non-invasive fat burn monitoring during exercise and rest. ${ }^{24} \mathrm{MOx}$ sensors, however, typically lack selectivity to detect target analytes in breath (>800 compounds $)^{25}$. Sufficient selectivity was obtained by material design only in few cases, for instance for acetone by $\varepsilon-\mathrm{WO}_{3},{ }^{26}$ ammonia by $\alpha-\mathrm{MoO}_{3}{ }^{27}$ or triethylamine by hollow $\mathrm{SnO}_{2}$ microfibers. ${ }^{28}$ In particular for isoprene, Ti-doped $\mathrm{ZnO}^{21}$ features selectivities in the range of 4 to 15 for breath-relevant acetone, ethanol and ammonia, however, it needs to be improved considering that these interferants are much more concentrated in the breath than isoprene. The major challenge in sensor material design with isoprene is the absence of distinct functional groups (hydroxyl, carbonyl, etc.) that can be exploited for selective sensor interaction.

Further molecular properties such as hydrophilicity and size can be exploited by filters to optimize sensing performance beyond chemoresistive surface reactivity. This concept has been applied for selective $\mathrm{CO}$ sensing ${ }^{29}$ through adsorption of hydrocarbon interferants on activated carbon filters and for selective formaldehyde detection using sizeselective microporous zeolite membranes. ${ }^{30}$ Also complex GC columns have been used in combination with sensors for selective detection of trichloroethylene, ${ }^{31}$ alcohols, ${ }^{32}$ aromatic vapors $^{33}$ or even for multiple compounds in breath. ${ }^{34}$ Such GC-sensor systems, however, require complex instrumentation (i.e. GC column, pre-concentration, ramped heating) and feature typically sluggish response and recovery times (e.g. $60 \mathrm{~min}^{33}$ for sampling and analysis of aromatic volatiles). Consequently, they seem hardly suitable for real-time portable breath isoprene detectors. 
Here, we present a novel filter-sensor concept for rapid and highly selective isoprene detection in complex breath mixtures at high relative humidity exploiting the hydrophobic nature of isoprene (Figure 1a). It consists of a packed bed of activated alumina featuring high porosity and surface area $\left(\sim 155 \mathrm{~m}^{2} / \mathrm{g}\right)^{35}$ to adsorb and retain hydrophilic breath compounds while isoprene passes unhindered (Figure 1b). Placed upstream of a highly sensitive but nonspecific, nanostructured Pt-doped $\mathrm{SnO}_{2}$ sensor, this filter is characterized for isoprene in gas mixtures with up to four components at $90 \%$ relative humidity $(\mathrm{RH})$. Finally, filter regeneration and long-term stability are evaluated for eight days of continuous operation.

\section{Experimental}

\section{Sensor fabrication}

Sensing films of Pt-doped $(0.15 \mathrm{~mol} \%) \mathrm{SnO}_{2}$ are prepared by flame spray pyrolysis (FSP) and directly deposited onto sensor substrates. ${ }^{36}$ For the FSP precursor solution, tin (II) ethylhexanoate (Strem, $~ 90 \%$ in 2-ethylhexanoic acid) and platinum acetylacetonate (Alfa Aesar, min. $48.0 \% \mathrm{Pt}$ ) are dissolved in xylene (Aldrich, $\geq 99.7 \%$ ) to give a total metal concentration of $0.5 \mathrm{~mol} / \mathrm{L}$ with a Pt-doping content of $0.15 \mathrm{~mol} \% .{ }^{37}$ The precursor is fed through a FSP nozzle with $5 \mathrm{~mL} / \mathrm{min}$ and dispersed with $5 \mathrm{~L} / \mathrm{min}$ oxygen at a pressure drop of 1.5 bar. This spray is ignited by a premixed, ring-shaped methane/oxygen $(1.25 / 3.2 \mathrm{~L} / \mathrm{min})$ flame ${ }^{38}$ while additional $5 \mathrm{~L} / \mathrm{min}$ of oxygen is supplied as sheath gas. Deposition takes place by thermophoresis ${ }^{36}$ of Pt-doped $\mathrm{SnO}_{2}$ nanoparticles onto sensor substrates mounted on a water-cooled holder at $20 \mathrm{~cm}$ height above the burner (HAB) for $2 \mathrm{~min}$. The applied $\mathrm{Al}_{2} \mathrm{O}_{3}$ substrates $(15 \mathrm{~mm} \times 13 \mathrm{~mm} \times 0.8 \mathrm{~mm}$, Electronic Design Center, Case Western Reserve University) feature interdigitated Pt electrodes (sputtered, $350 \mu \mathrm{m}$ width and spacing) and a Pt heater on the back. To improve adhesion and cohesion of these FSP-deposited nanoparticle films, they are in-situ annealed ${ }^{39}$ with a particle-free flame. For this, the substrate is lowered to a HAB of $14.5 \mathrm{~cm}$ and annealed for $30 \mathrm{~s}$ by a xylene flame $(11 \mathrm{ml} / \mathrm{min}$ xylene dispersed by 
$5 \mathrm{~L} / \mathrm{min}$ oxygen at 1.5 bar) with the same methane/oxygen flame and sheath gas as for the sensing film deposition. Prior to testing, sensors are thermally stabilized by heating in an oven (Carbolite $\mathrm{GmbH})$ at $500{ }^{\circ} \mathrm{C}$ for $5 \mathrm{~h}$.

\section{Filter fabrication}

The filter consists of a packed bed of $1 \mathrm{~g}$ activated alumina (Sigma-Aldrich, neutral $\mathrm{pH}$ when in water, 50-300 mesh, $155 \mathrm{~m}^{2} / \mathrm{g}$ ) inside a Teflon tube (10 cm length, $15 \mathrm{~mm}$ inner diameter) and is firmly secured downstream by a porous, inert Teflon frit and upstream by an inert glass wool plug (Figure 2a). On both ends of the Teflon tube, tapered Swagelok connectors expand and contract the gas flow homogeneously to ensure utilization of the entire filter cross section and avoid stagnant zones. Freshly prepared filters are flushed with $1 \mathrm{~L} / \mathrm{min}$ air at $90 \% \mathrm{RH}$ for at least $12 \mathrm{~h}$ to saturate the alumina surface with humidity and guarantee equilibrium conditions.

\section{Gas evaluation}

The filter-sensor system (Figure $2 \mathrm{~b}$ ) consists of the gas delivery, ${ }^{27}$ activated alumina filter and Pt-doped $\mathrm{SnO}_{2}$ sensor. The sensor is mounted on a Macor holder and installed inside a Teflon sensor chamber ${ }^{40}$ where it is heated to $400{ }^{\circ} \mathrm{C}$ by DC current (R\&S HMC8043, Germany) by the substrate back-heater. The temperature is maintained by utilizing the $\mathrm{Pt}$ heater as resistance temperature detector (RTD), monitored with a multimeter (Keithley, 2700, USA). The ohmic resistance of the sensing film between the interdigitated electrodes is measured by the same multimeter. Sensor responses are evaluated as:

$$
S=\frac{R_{\text {Air }}}{R_{\text {Analyte }}}-1
$$

where $R_{\text {Air }}$ and $R_{\text {Analyte }}$ denote the sensor film resistances measured in synthetic air without and with a given analyte concentration, respectively. The sensor response ( $\left.t_{90}\right)$ and filter 
breakthrough time $\left(t_{5}\right)$ for an analyte are defined as the time to reach $90 \%$ and $5 \%{ }^{41}$ of the steady-state response, respectively.

Sensor measurements were performed at a total gas flow rate of $1 \mathrm{~L} / \mathrm{min}$ and $90 \% \mathrm{RH}$. Gas mixtures were prepared by first admixing the analyte gas standards with dry synthetic air (PanGas, hydrocarbon-free grade) by calibrated mass flow controllers (Bronkhorst, Netherlands). Analyte gases are supplied from calibrated gas standards (PanGas) in synthetic air at concentrations of $10 \mathrm{ppm}$ for acetone, isoprene, ammonia and $50 \mathrm{ppm}$ for ethanol, methanol, ammonia. These analytes are present in breath at relatively high concentration and are selected because of their known interaction with Pt-doped $\mathrm{SnO}_{2}$ sensors, unlike other breath compounds like $\mathrm{H}_{2}{ }^{42}$. The humidity level was set by guiding synthetic air through a water bubbler and dosing it to the gas mixture stream to obtain the desired relative humidity level as verified by a humidity sensor (SHT2x, Sensirion AG). Teflon gas lines were heated to $\sim 50{ }^{\circ} \mathrm{C}$ to avoid condensation and adsorption. ${ }^{27}$

\section{Results and Discussion}

\section{Filter effect on isoprene selectivity}

Figure 3a shows the sensor response profiles of Pt-doped $\mathrm{SnO}_{2}$ to $500 \mathrm{ppb}$ of isoprene (blue), acetone (red), ethanol (orange), methanol (green) and ammonia (purple) at breath-relevant ${ }^{43}$ 90\% RH. These analytes represent major components in exhaled breath with median concentrations higher than the $106 \mathrm{ppb}^{44}$ of isoprene (e.g. ammonia $833 \mathrm{ppb}^{45}$ ). The sensor detects all these analytes within a few seconds (e.g. $t_{90}=2.9 \mathrm{~s}$ for isoprene), sufficiently fast for real-time breath analysis. However, it cannot distinguish them. In fact, when evaluating the individual responses after $30 \mathrm{~s}$ (Figure 3b), representing a typical breath test duration, ${ }^{24}$ the rather non-specific nature of Pt-doped $\mathrm{SnO}_{2}$ becomes evident, in line with previous results. ${ }^{37}$ Consequently, this sensor cannot measure isoprene selectively in breath mixtures. 
Most importantly, when adding the activated alumina filter (Figure 3c), an identical response for isoprene is obtained with barely affected response dynamics ( $t_{90}$ of $4.2 \mathrm{~s}$ ), while all hydrophilic analytes are held back. This results in unprecedented high isoprene-selectivity (>100) to all analytes (Figure 3d). Only after $40 \mathrm{~s}$, the sensor starts to detect acetone while it takes even longer for the other hydrophilic analytes (full responses in Figure S-1). In specific, breakthrough times $t_{5}$ strongly vary between the analytes from 50 to $300 \mathrm{~s}$ for acetone to ammonia, respectively (Figure $3 \mathrm{~d}$ in parenthesis). Important also, after analyte exposure is stopped, the sensor fully recovers the initial baseline enabling repeated measurements. Note that the breakthrough and regeneration times of hydrophilic analytes can be controlled by the activated alumina filter loading, while the response time of isoprene is barely affected (shown in Figure S-2). One gram of activated alumina was selected for deeper investigation to guarantee an interferent-free detection of isoprene, fast filter regeneration for repeated measurements and a low pressure drop of $\sim 20$ mbar, sufficiently small ${ }^{24}$ for breath analyzers.

The selectivities achieved by the proposed filter-sensor system clearly outperform state-of-the-art chemoresistive isoprene sensors. Highest isoprene selectivities obtained so far were in the range of 4 to 15 for acetone, ethanol and ammonia with Ti-doped $\mathrm{ZnO} .^{21}$ Other chemoresistive sensors of $\mathrm{TiO}_{2}{ }^{46}$ and $h-\mathrm{WO}_{3}{ }^{47}$ could detect isoprene but did not achieve selectivities >4. Only the chemiluminescence detector Fast Isoprene Sensor (FIS, HillsScientific) features similarly high isoprene selectivities, but this device is hardly suitable for routine measurements by a widespread population due to its high cost (base module $\left.\$ 42^{\prime} 000\right)$, weight (18 kg) and requirement of an external ozonizer. ${ }^{48}$

\section{Separation mechanism}

When passing through the filter, hydrophilic analytes (i.e. alcohols, ketones, ammonia) are retained by adsorption on the activated alumina (Figure 1b) featuring extremely large surface area $\left(155 \mathrm{~m}^{2} / \mathrm{g}\right) \cdot{ }^{35}$ Note that the alumina surface should be mostly covered by bound water ${ }^{49}$ 
at $90 \% \mathrm{RH}$ because of its high affinity, ${ }^{50}$ so gas ad-/absorption may occur on/in that layer as well. ${ }^{51}$ As a result, the strength of analyte-filter interaction should be governed by the ability for hydrogen bonding, ${ }^{52}$ with ammonia having four, ethanol and methanol three, acetone only two and isoprene zero hydrogen bonding sites (oxygen/nitrogen lone electron pairs \& hydrogen atoms). This matches well with the $t_{5}$ of the analytes, following the same order (Figure 3d). Note that any water layer formed by RH (i.e. surface hydration) weakens sorption of hydrophilic compounds, as indicated by shorter $t_{5}$ for acetone at $50 \% \mathrm{RH}$ (Figure S-3) and consistent with literature. ${ }^{53}$

In contrast, isoprene is hydrophobic and passes through the filter unscathed, consistent with the sensing results (compare Figure 3 a to c). Isoprene is the major hydrocarbon in breath (up to $70 \%$ of total) ${ }^{54}$ but also other hydrophobic species (e.g. ethane, pentane $)^{55}$ should pass the filter unaffected and cause measurement errors, if interfering with the sensor. However, this can be prevented by combining this modular filter with an additional size-selective zeolite membrane to remove larger hydrocarbons (as applied already for sensing of formaldehyde $)^{30}$ or with an E-nose that can distinguish single components in gas mixtures with small prediction errors. ${ }^{37}$

\section{Gas mixtures}

Human breath consists of $>800$ compounds, ${ }^{25}$ so evaluation of the proposed filter-sensor system in gas mixtures is crucial. Figure 4a shows the Pt-doped $\mathrm{SnO}_{2}$ response with filter to two consecutive $30 \mathrm{~s}$ exposures of simultaneous $500 \mathrm{ppb}$ isoprene and acetone (grey-shaded). Most interestingly, two distinct responses are observed for each exposure. The first one increases immediately upon exposure, stays stable at $\sim 3$ and rapidly decreases after it. It is associated solely to isoprene, as evident from single isoprene exposure at the same conditions (blue line, Figure 4b) resulting in an identical response profile. The second response in Figure $4 \mathrm{a}$ is delayed, starting after $\sim 40 \mathrm{~s}$ and spreading out over a couple of minutes. This 
response is related to acetone. In fact, it is identical to single acetone exposure (red line, Figure $4 \mathrm{~b}$ ) and the breakthrough time, $t_{5}$, similar to longer exposures (Figure $3 \mathrm{c}$ ). As a result, the outstanding separation properties of the filter are preserved also in binary mixtures and isoprene is detected selectively during such short breath-realistic exposures. Remarkable also, the filter-sensor system recovers fully within $5 \mathrm{~min}$ and gives repeatable signals for continuous application. Note that these results were cross-validated by a bench-top protontransfer-reaction time-of-flight mass spectrometer (PTR-TOF-MS) (Figure S-4).

\section{Low-ppb isoprene detection}

Breath isoprene levels can be at low ppb concentration, therefore, the Pt-doped $\mathrm{SnO}_{2}$ sensor with filter was exposed to low but breath-relevant isoprene concentrations of 20,10 and $5 \mathrm{ppb}$ at $90 \% \mathrm{RH}$ (Figure 5a). The sensor rapidly responds to these levels with high signal-to-noise ratio (>90) and can distinguish them clearly. When flushed with air, the filter-sensor system quickly regenerates (within $3 \mathrm{~min}$ ) the original baseline and gives identical responses after repeated exposures to 20 and $10 \mathrm{ppb}$, indicating excellent reproducibility.

This filter-sensor system is applicable over the entire breath-relevant concentration range of isoprene from 5 to $500 \mathrm{ppb}$ at $90 \% \mathrm{RH}$ (blue crosses in Figure $5 \mathrm{~b}$ ). The resulting sensor responses follow a power law $\left(S \sim c^{n}\right.$ with $\left.n=0.64, R^{2}>0.995\right)$, in agreement with non-linear diffusion-reaction theory. ${ }^{56}$ Remarkably as well, the presence of the filter does not compromise the sensor response to isoprene in comparison to that without filter (Figure 5b, red circles).

\section{Operational stability with simulated breath pulses}

To challenge the filter-sensor system further, operational stability was evaluated during continuous operation for eight days at $90 \% \mathrm{RH}$. To simulate daily breath isoprene measurement, three consecutive pulses of a gas mixture containing breath-median 
concentrations of isoprene $(106 \mathrm{ppb})^{44}$, acetone $(477 \mathrm{ppb})^{45}$, methanol $(461 \mathrm{ppb})^{57}$ and ammonia $(833 \mathrm{ppb})^{45}$ were applied daily. Figure $6 \mathrm{a}$ shows the sensor responses during such a measurement cycle after six days. Isoprene is registered quickly and accurately from the first plateau during the exposure while all polar analytes are held back resulting in a delayed and accumulated spread response, similar to binary mixtures (Figure 4a). This enables precise measurement of isoprene even after several days of continuous operation despite the more concentrated interferants. Indeed, when evaluating the sensor baseline (red circles in Figure 6b) and isoprene response resistance (blue squares) during these eight days, both are quite stable ( $<6 \%$ change), corresponding to a change in sensor response $<20 \%$ (Figure S-5). This is consistent with previous results on Pt-doped $\mathrm{SnO}_{2}$ sensors without filters when operated for 20 days, ${ }^{58}$ and could be corrected by an additional processing algorithm. ${ }^{59}$ The filter should not contribute to this drift since it regenerates completely after each simulated breath exposure (Figure 6a), as confirmed by bench-top PTR-TOF-MS (Figure S-4). Consequently, the filter-sensor system is promising for breath isoprene measurement, but this needs to be confirmed with tests on humans as was done recently ${ }^{24}$ with acetone and $\mathrm{Si}$-doped $\mathrm{WO}_{3}$ sensors to monitor body fat burn during exercise and rest.

\section{Conclusions}

A filter-sensor concept was introduced for rapid and highly selective isoprene detection in breath-relevant gas mixtures. The filter is a packed bed of activated alumina offering large surface area to retain hydrophilic compounds without affecting hydrophobic isoprene. As proof-of-concept, filters of activated alumina turned a highly sensitive, non-specific Pt-doped $\mathrm{SnO}_{2}$ sensor isoprene-selective (>100) to breath-relevant acetone, ammonia, ethanol and methanol at $90 \% \mathrm{RH}$. That way, isoprene is detected selectively down to $5 \mathrm{ppb}$ within seconds, more than sufficient for real-time breath analysis. Even when operated continuously for eight days, this filter-sensor system showed stable performance with reproducible 
(regeneration within $10 \mathrm{~min}$ ) and accurate isoprene detection in simulated breath mixtures. Based on their small size and modular design, they can be integrated readily into inexpensive and portable breath analyzers promising for non-invasive monitoring of blood cholesterol levels and other patho/physiological conditions.

\section{Supporting Information}

The following files are available free of charge:

Supporting Information for Publication. Full sensor responses with filter for acetone, ethanol, methanol and ammonia, results at different filter loadings, sensor response with filter at different relative humidity, proton-transfer-reaction time-of-flight mass spectrometer analysis results, stability of sensor response during eight days of testing.

\section{Acknowledgment}

Financial support by the Swiss National Science Foundation (Project Grant 200021_159763/1 and R'Equip Grant 206021_170729) is gratefully acknowledged. 


\section{References}

1. Mendis, S.; Puska, P.; Norrving, B., Global atlas on cardiovascular disease prevention and control. World Health Organization: 2011.

2. Feigin, V., Global, regional, and national life expectancy, all-cause mortality, and causespecific mortality for 249 causes of death, 1980-2015: a systematic analysis for the Global Burden of Disease Study 2015. Lancet 2016, 388 (10053), 1459-1544.

3. McGill, H. C.; McMahan, C. A.; Gidding, S. S., Preventing heart disease in the $21^{\text {st }}$ century. Circulation 2008, 117 (9), 1216-1227.

4. Stone, N. J.; Robinson, J. G.; Lichtenstein, A. H.; Bairey Merz, C. N.; Blum, C. B.; Eckel, R. H.; Goldberg, A. C.; Gordon, D.; Levy, D.; Lloyd-Jones, D. M.; McBride, P.; Schwartz, J. S.; Shero, S. T.; Smith, S. C.; Watson, K.; Wilson, P. W. F., 2013 ACC/AHA guideline on the treatment of blood cholesterol to reduce atherosclerotic cardiovascular risk in adults: A report of the american college of cardiology/american heart association task force on practice guidelines. J. Am. Coll. Cardiol. 2014, 63 (25, Part B), 2889-2934.

5. Bookstein, L.; Gidding, S. S.; Donovan, M.; Smith, F. A., Day-to-day variability of serum cholesterol, triglyceride, and high-density lipoprotein cholesterol levels. Arch. Intern. Med. 1990, 150 (8), 1653-1657.

6. Risby, T. H.; Solga, S. F., Current status of clinical breath analysis. Appl. Phys. B 2006, 85 (2), 421-426.

7. Deneris, E. S.; Stein, R. A.; Mead, J. F., Invitro biosynthesis of isoprene from mevalonate utilizing a rat liver cytosolic fraction. Biochem. Biophys. Res. Commun. 1984, 123 (2), 691-696.

8. Španěl, P.; Davies, S.; Smith, D., Quantification of breath isoprene using the selected ion flow tube mass spectrometric analytical method. Rapid Commun. Mass Spectrom. 1999, 13 (17), 1733-1738.

9. Nelson, N.; Lagesson, V.; Nosratabadi, A. R.; Ludvigsson, J.; Tagesson, C., Exhaled isoprene and acetone in newborn infants and in children with diabetes mellitus. Pediatr. Res. 1998, 44 (3), 363-367.

10. Smith, D.; Španěl, P.; Enderby, B.; Lenney, W.; Turner, C.; Davies, S. J., Isoprene levels in the exhaled breath of 200 healthy pupils within the age range 7-18 years studied using SIFT-MS. J. Breath. Res. 2009, 4 (1), 017101.

11. Stone, B. G.; Besse, T. J.; Duane, W. C.; Evans, C. D.; DeMaster, E. G., Effect of regulating cholesterol biosynthesis on breath isoprene excretion in men. Lipids 1993, 28 (8), 705-708.

12. Karl, T.; Prazeller, P.; Mayr, D.; Jordan, A.; Rieder, J.; Fall, R.; Lindinger, W., Human breath isoprene and its relation to blood cholesterol levels: New measurements and modeling. J. Appl. Physiol. 2001, 91 (2), 762-770.

13. Mashir, A.; Paschke, K.; Van Duin, D.; Shrestha, N.; Laskowski, D.; Storer, M.; YenLieberman, B.; Gordon, S.; Aytekin, M.; Dweik, R., Effect of the influenza A (H1N1) live attenuated intranasal vaccine on nitric oxide (FENO) and other volatiles in exhaled breath. J. Breath. Res. 2011, 5 (3), 037107.

14. Davies, S.; Španel, P.; Smith, D., A new 'online' method to measure increased exhaled isoprene in end-stage renal failure. Nephrol., Dial., Transplant. 2001, 16 (4), 836-839.

15. King, J.; Kupferthaler, A.; Unterkofler, K.; Koc, H.; Teschl, S.; Teschl, G.; Miekisch, W.; Schubert, J.; Hinterhuber, H.; Amann, A., Isoprene and acetone concentration profiles during exercise on an ergometer. J. Breath. Res. 2009, 3 (2), 027006.

16. Bajtarevic, A.; Ager, C.; Pienz, M.; Klieber, M.; Schwarz, K.; Ligor, M.; Ligor, T.; Filipiak, W.; Denz, H.; Fiegl, M.; Hilbe, W.; Weiss, W.; Lukas, P.; Jamnig, H.; Hackl, 
M.; Haidenberger, A.; Buszewski, B.; Miekisch, W.; Schubert, J.; Amann, A., Noninvasive detection of lung cancer by analysis of exhaled breath. BMC Cancer 2009, $9(1), 348$.

17. Alkhouri, N.; Singh, T.; Alsabbagh, E.; Guirguis, J.; Chami, T.; Hanouneh, I.; Grove, D.; Lopez, R.; Dweik, R., Isoprene in the exhaled breath is a novel biomarker for advanced fibrosis in patients with chronic liver disease: A pilot study. Clin. Transl. Gastroenterol. 2015, 6, e112.

18. Sanchez, J. M.; Sacks, R. D., GC analysis of human breath with a series-coupled column ensemble and a multibed sorption trap. Anal. Chem. 2003, 75 (10), 2231-2236.

19. Ohira, S.-I.; Li, J.; Lonneman, W. A.; Dasgupta, P. K.; Toda, K., Can breath isoprene be measured by ozone chemiluminescence? Anal. Chem. 2007, 79 (7), 2641-2649.

20. Clayden, J.; Greeves, N.; Warren, S., Organic chemistry. $2^{\text {nd }}$ ed.; Oxford University Press: Oxford, 2012.

21. Güntner, A. T.; Pineau, N. J.; Chie, D.; Krumeich, F.; Pratsinis, S. E., Selective sensing of isoprene by Ti-doped $\mathrm{ZnO}$ for breath diagnostics. J. Mater. Chem. B 2016, 4 (32), 5358-5366.

22. McCartney, M. M.; Zrodnikov, Y.; Fung, A. G.; LeVasseur, M. K.; Pedersen, J. M.; Zamuruyev, K. O.; Aksenov, A. A.; Kenyon, N. J.; Davis, C. E., An easy to manufacture micro gas preconcentrator for chemical sensing applications. ACS Sens. 2017, 2 (8), 1167-1174.

23. Righettoni, M.; Ragnoni, A.; Güntner, A. T.; Loccioni, C.; Pratsinis, S. E.; Risby, T. H., Monitoring breath markers under controlled conditions. J. Breath. Res. 2015, 9, 047101.

24. Güntner, A. T.; Sievi, N. A.; Theodore, S. J.; Gulich, T.; Kohler, M.; Pratsinis, S. E., Noninvasive body fat burn monitoring from exhaled acetone with $\mathrm{Si}$-doped $\mathrm{WO}_{3}$-sensing nanoparticles. Anal. Chem. 2017, 89 (19), 10578-10584.

25. de Lacy Costello, B.; Amann, A.; Al-Kateb, H.; Flynn, C.; Filipiak, W.; Khalid, T.; Osborne, D.; Ratcliffe, N. M., A review of the volatiles from the healthy human body. $J$. Breath. Res. 2014, 8 (1), 014001.

26. Wang, L.; Teleki, A.; Pratsinis, S. E.; Gouma, P. I., Ferroelectric $\mathrm{WO}_{3}$ nanoparticles for acetone selective detection. Chem. Mater. 2008, 20, 4794-4796.

27. Güntner, A. T.; Righettoni, M.; Pratsinis, S. E., Selective sensing of $\mathrm{NH}_{3}$ by Si-doped $\alpha-$ $\mathrm{MoO}_{3}$ for breath analysis. Sens. Actuators, B 2016, 223, 266-273.

28. Zou, Y.; Chen, S.; Sun, J.; Liu, J.; Che, Y.; Liu, X.; Zhang, J.; Yang, D., Highly efficient gas sensor using a hollow $\mathrm{SnO}_{2}$ microfiber for triethylamine detection. ACS Sens. 2017, 2 (7), 897-902.

29. Schweizer-Berberich, M.; Strathmann, S.; Göpel, W.; Sharma, R.; Peyre-Lavigne, A., Filters for tin dioxide CO gas sensors to pass the UL2034 standard. Sens. Actuators, $B$ 2000, 66 (1-3), 34-36.

30. Güntner, A. T.; Abegg, S.; Wegner, K.; Pratsinis, S. E., Zeolite membranes for highly selective formaldehyde sensors. Sens. Actuators, B 2018, 257, 916-923.

31. Kim, S. K.; Chang, H.; Zellers, E. T., Microfabricated gas chromatograph for the selective determination of trichloroethylene vapor at sub-parts-per-billion concentrations in complex mixtures. Anal. Chem. 2011, 83 (18), 7198-7206.

32. Wanekaya, A. K.; Uematsu, M.; Breimer, M.; Sadik, O. A., Multicomponent analysis of alcohol vapors using integrated gas chromatography with sensor arrays. Sens. Actuators, B 2005, 110 (1), 41-48.

33. Zampolli, S.; Elmi, I.; Mancarella, F.; Betti, P.; Dalcanale, E.; Cardinali, G. C.; Severi, M., Real-time monitoring of sub-ppb concentrations of aromatic volatiles with a MEMSenabled miniaturized gas-chromatograph. Sens. Actuators, B 2009, 141 (1), 322-328. 
34. Itoh, T.; Miwa, T.; Tsuruta, A.; Akamatsu, T.; Izu, N.; Shin, W.; Park, J.; Hida, T.; Eda, T.; Setoguchi, Y., Development of an exhaled breath monitoring system with semiconductive gas sensors, a gas condenser unit, and gas chromatograph columns. Sensors 2016, 16 (11), 1891.

35. Yang, R. T., Gas separation by adsorption processes. Imperial College Press London, 1997.

36. Mädler, L.; Roessler, A.; Pratsinis, S. E.; Sahm, T.; Gurlo, A.; Barsan, N.; Weimar, U., Direct formation of highly porous gas-sensing films by in situ thermophoretic deposition of flame-made $\mathrm{Pt} / \mathrm{SnO}_{2}$ nanoparticles. Sens. Actuators, B 2006, 114, 283-295.

37. Güntner, A. T.; Koren, V.; Chikkadi, K.; Righettoni, M.; Pratsinis, S. E., E-nose sensing of low-ppb formaldehyde in gas mixtures at high relative humidity for breath screening of lung cancer? ACS Sens. 2016, 1, 528-535.

38. Mädler, L.; Kammler, H. K.; Mueller, R.; Pratsinis, S. E., Controlled synthesis of nanostructured particles by flame spray pyrolysis. J. Aerosol Sci. 2002, 33 (2), 369-389.

39. Tricoli, A.; Graf, M.; Mayer, F.; Kühne, S.; Hierlemann, A.; Pratsinis, S. E., Micropatterning layers by flame aerosol deposition-annealing. Adv. Mater. 2008, 20, 3005-3010.

40. Righettoni, M.; Tricoli, A.; Gass, S.; Schmid, A.; Amann, A.; Pratsinis, S. E., Breath acetone monitoring by portable $\mathrm{Si}: \mathrm{WO}_{3}$ gas sensors. Anal. Chim. Acta 2012, 738, 69-75.

41. Geankoplis, C. J., Transport processes and separation process principles. $4^{\text {th }} \mathrm{ed}$.; Prentice Hall: 2003.

42. Kim, B.-Y.; Cho, J. S.; Yoon, J.-W.; Na, C. W.; Lee, C.-S.; Ahn, J. H.; Kang, Y. C.; Lee, J.-H., Extremely sensitive ethanol sensor using Pt-doped $\mathrm{SnO}_{2}$ hollow nanospheres prepared by Kirkendall diffusion. Sens. Actuators, B 2016, 234, 353-360.

43. Ferrus, L.; Guenard, H.; Vardon, G.; Varene, P., Respiratory water loss. Respir. Physiol. 1980, 39 (3), 367-381.

44. Turner, C.; Španěl, P.; Smith, D., A longitudinal study of breath isoprene in healthy volunteers using selected ion flow tube mass spectrometry (SIFT-MS). Physiol. Meas. 2005, 27 (1), 13-22.

45. Claire, T.; Patrik, Š.; David, S., A longitudinal study of ammonia, acetone and propanol in the exhaled breath of 30 subjects using selected ion flow tube mass spectrometry, SIFT-MS. Physiol. Meas. 2006, 27 (4), 321-337.

46. Teleki, A.; Pratsinis, S. E.; Kalyanasundaram, K.; Gouma, P. I., Sensing of organic vapors by flame-made $\mathrm{TiO}_{2}$ nanoparticles. Sens. Actuators, B 2006, 119, 683-690.

47. Gouma, P.-I.; Wang, L.; Simon, S.; Stanacevic, M., Novel isoprene sensor for a flu virus breath monitor. Sensors 2017, 17 (1), 199.

48. Fast Isoprene Sensor. http://www.hills-scientific.com/ (accessed 17/11/27).

49. Castro, R. H. R.; Quach, D. V., Analysis of anhydrous and hydrated surface energies of gamma- $\mathrm{Al}_{2} \mathrm{O}_{3}$ by water adsorption microcalorimetry. J. Phys. Chem. C 2012, 116 (46), 24726-24733.

50. Sircar, S.; Rao, M.; Golden, T., Chapter 2.12 Drying of gases and liquids by activated alumina. Stud. Surf. Sci. Catal. 1996, 99, 629-646.

51. Roth, C. M.; Goss, K.-U.; Schwarzenbach, R. P., Adsorption of a diverse set of organic vapors on the bulk water surface. J. Colloid Interface Sci. 2002, 252 (1), 21-30.

52. Delle Site, A., Factors affecting sorption of organic compounds in natural sorbent/water systems and sorption coefficients for selected pollutants. A review. J. Phys. Chem. Ref. Data 2001, 30 (1), 187-439.

53. Goss, K.-U.; Eisenreich, S. J., Adsorption of VOCs from the gas phase to different minerals and a mineral mixture. Environ. Sci. Technol. 1996, 30 (7), 2135-2142. 
54. Gelmont, D.; Stein, R. A.; Mead, J. F., Isoprene - the main hydrocarbon in human breath. Biochem. Biophys. Res. Commun. 1981, 99 (4), 1456-1460.

55. Kneepkens, C. F.; Lepage, G.; Roy, C. C., The potential of the hydrocarbon breath test as a measure of lipid peroxidation. Free Radicals Biol. Med. 1994, 17 (2), 127-160.

56. Gardner, J. W., A non-linear diffusion-reaction model of electrical conduction in semiconductor gas sensors. Sens. Actuators, B 1990, 1 (1), 166-170.

57. Turner, C.; Španěl, P.; Smith, D., A longitudinal study of methanol in the exhaled breath of 30 healthy volunteers using selected ion flow tube mass spectrometry, SIFT-MS. Physiol. Meas. 2006, 27 (7), 637-648.

58. Mädler, L.; Sahm, T.; Gurlo, A.; Grunwaldt, J. D.; Barsan, N.; Weimar, U.; Pratsinis, S. E., Sensing low concentrations of $\mathrm{CO}$ using flame-spray-made $\mathrm{Pt} / \mathrm{SnO}_{2}$ nanoparticles. $J$. Nanopart. Res. 2006, 8, 783-796.

59. Artursson, T.; Eklöv, T.; Lundström, I.; Mårtensson, P.; Sjöström, M.; Holmberg, M., Drift correction for gas sensors using multivariate methods. J. Chemom. 2000, 14 (5-6), 711-723. 


\section{Figure \& Captions}

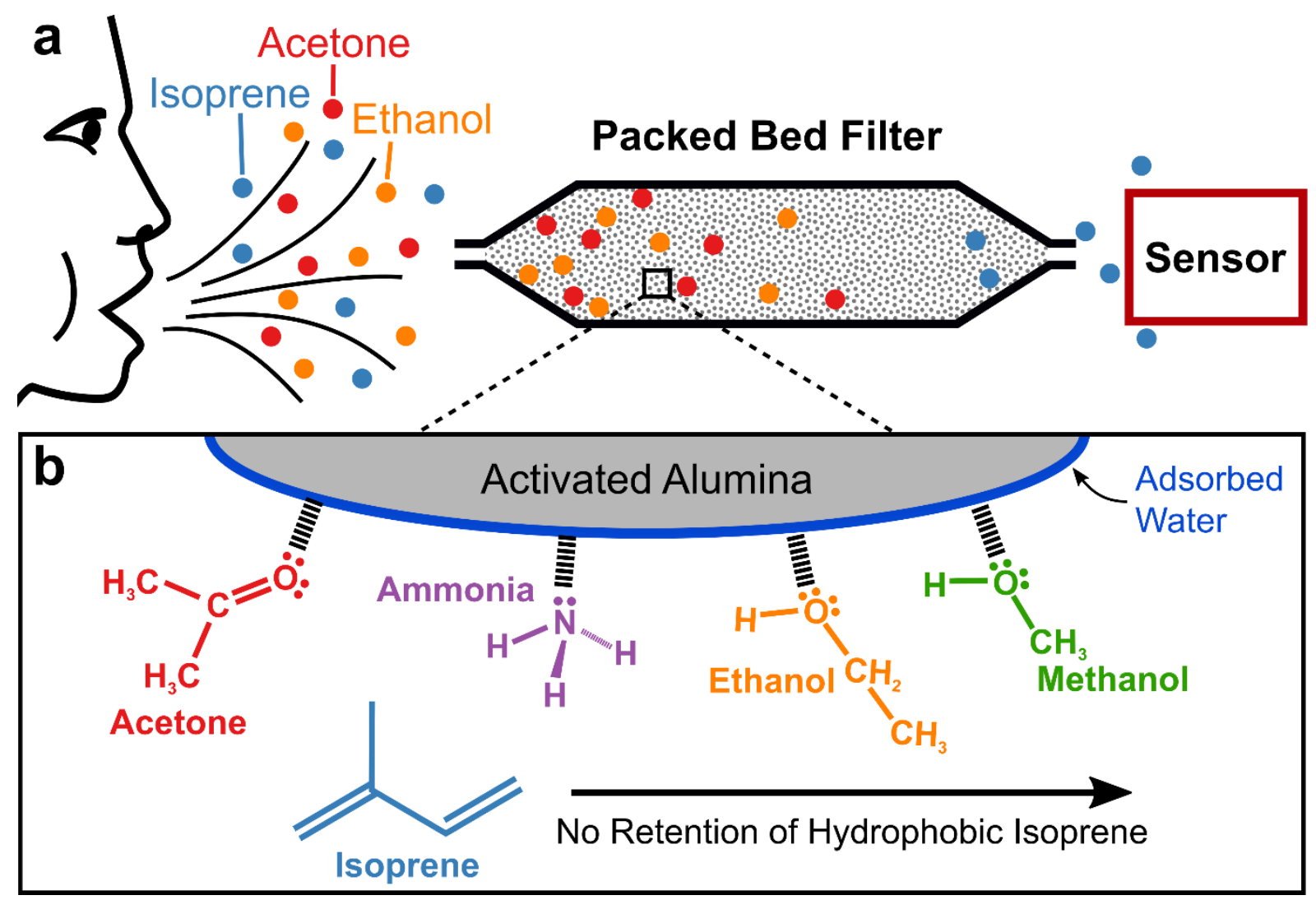

Figure 1. Filter-sensor concept of selective isoprene detection in complex gas mixtures: (a)

Breath is filtered through a packed bed filter upstream of a highly sensitive but non-specific gas sensor. (b) Hydrophilic analytes (e.g. acetone, ammonia, ethanol, methanol, etc.) are adsorbed and retained on the activated alumina and on the adsorbed water layer. In contrast, hydrophobic isoprene does not interact with the filter. This enables highly selective isoprene detection at low ppb concentration in real-time.

(show double column) 

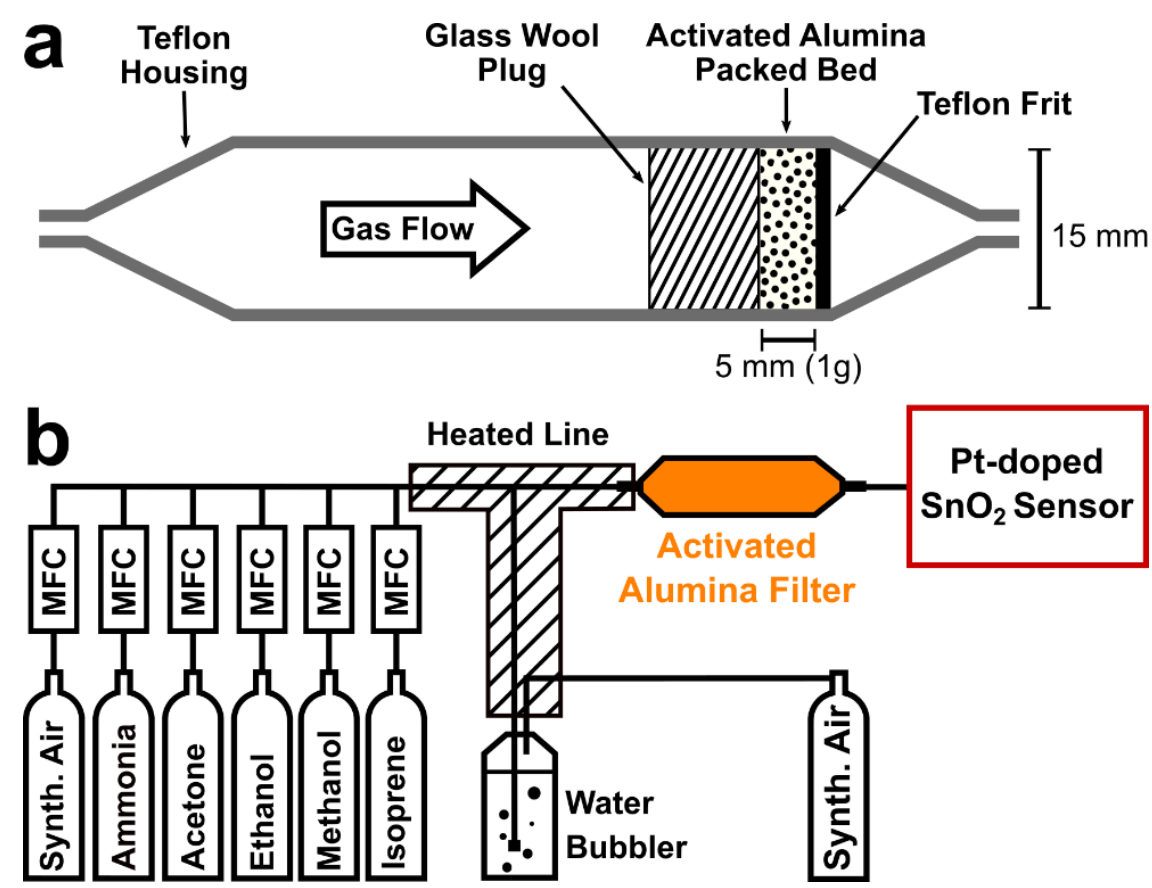

Figure 2. Schematic of the activated alumina filter (a) and the gas measurement setup (b). (show single column) 

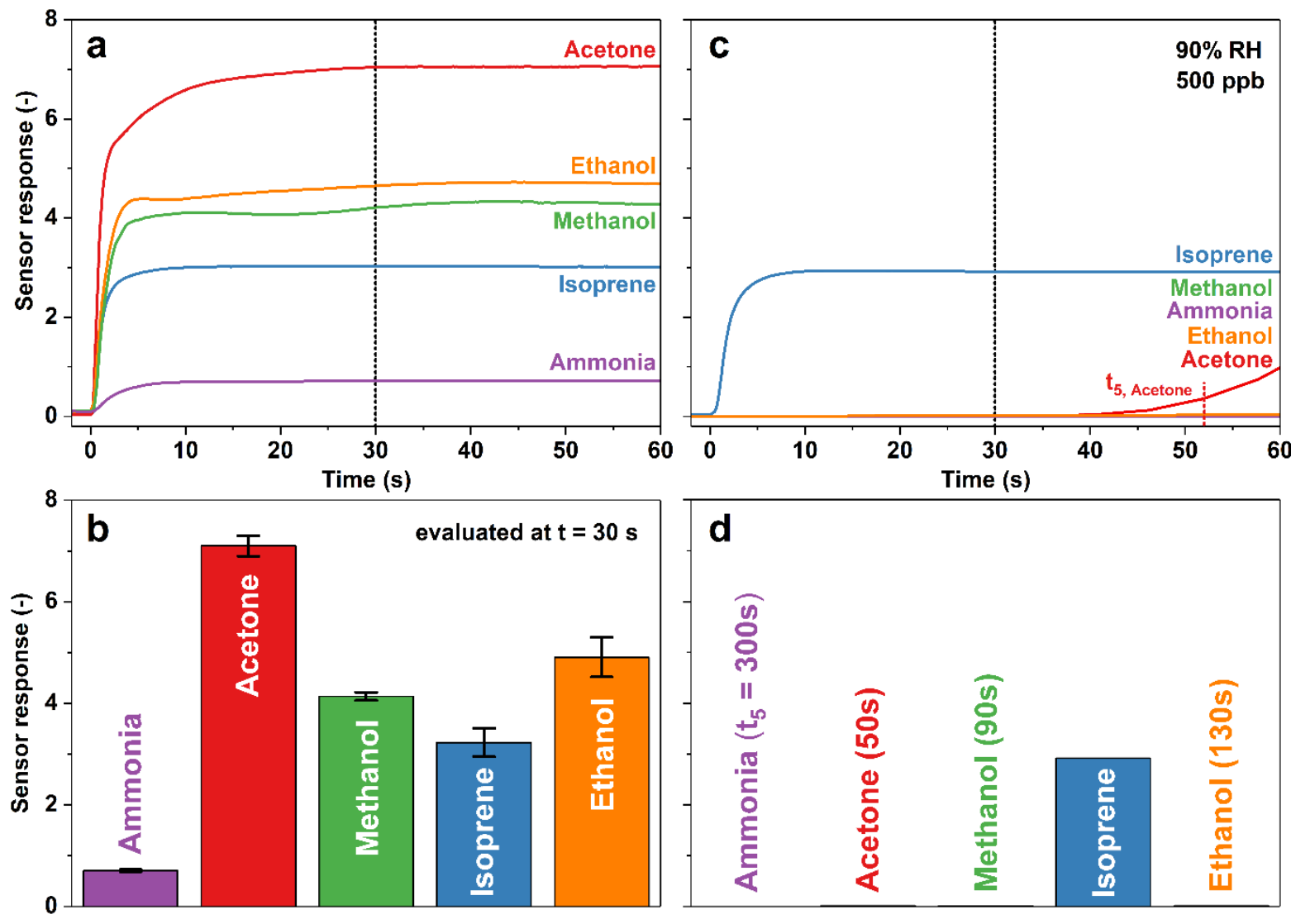

Figure 3. The responses of a Pt-doped $\mathrm{SnO}_{2}$ sensor at $90 \% \mathrm{RH}$ to $500 \mathrm{ppb}$ of isoprene (blue), acetone (red), ethanol (orange), methanol (green) and ammonia (purple) without (a, b) and with a $1 \mathrm{~g}$ activated alumina filter $(\mathbf{c}, \mathbf{d})$. The single Pt-doped $\mathrm{SnO}_{2}$ sensor without filter is rather non-specific when evaluating the responses after $30 \mathrm{~s}$ (b). Error bars indicate the response variability of three such sensors, which is smaller than $10 \%$. Using the filter, hydrophilic analytes are held back until their characteristic breakthrough time $t_{5}$, while the response of isoprene is unchanged (c). This results in very high isoprene-selectivity $(>100)$ when evaluated, for instance, after $30 \mathrm{~s}$ (d).

(show double column) 


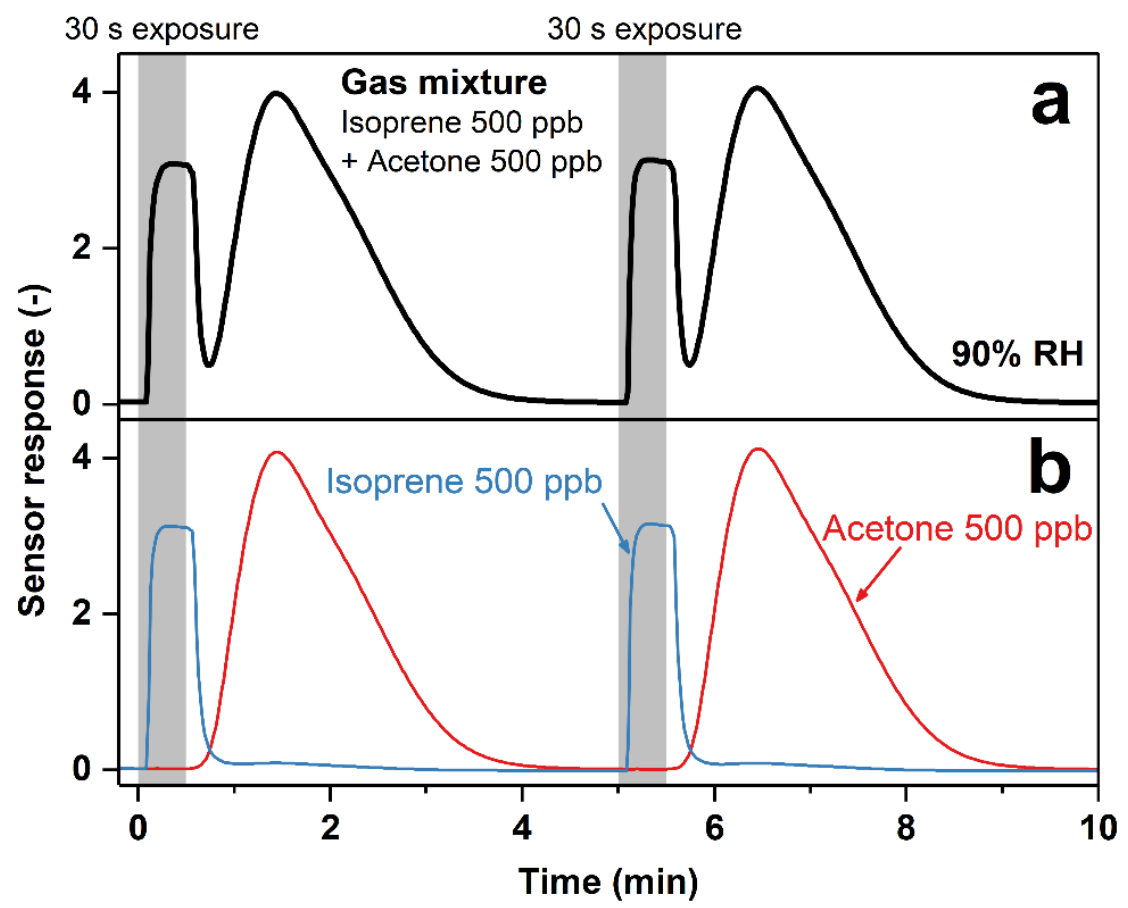

Figure 4. (a) Pt-doped $\mathrm{SnO}_{2}$ sensor response with filter to a gas mixture of $500 \mathrm{ppb}$ isoprene and acetone at 90\% RH. Two consecutive pulses of $30 \mathrm{~s}$ (grey-shaded) were applied at 0 and 4.5 min, simulating breath pulses. (b) The single gas responses to $500 \mathrm{ppb}$ of isoprene (blue) and acetone (red) at $90 \% \mathrm{RH}$.

(show single column) 

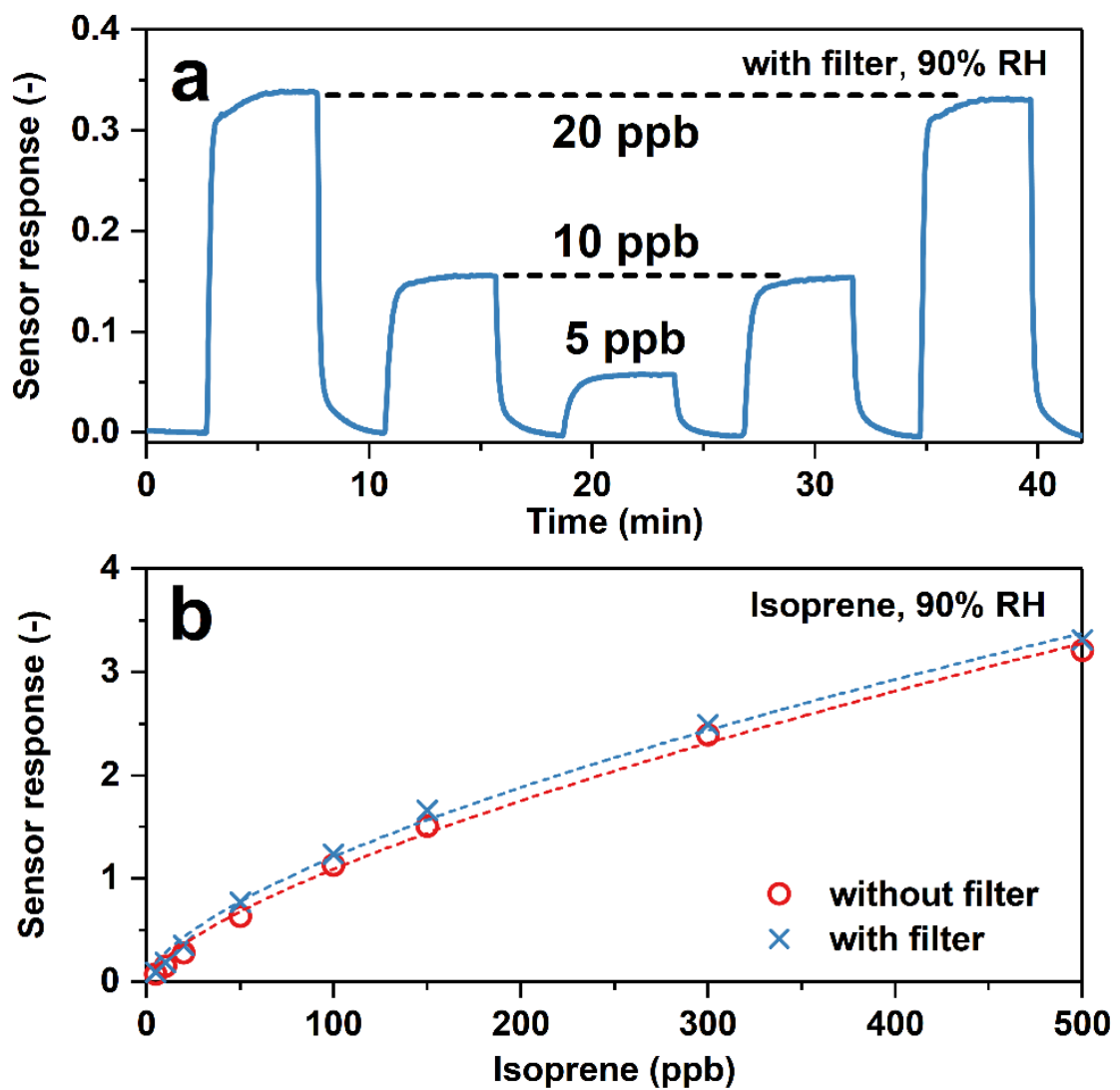

Figure 5. (a) Pt-doped $\mathrm{SnO}_{2}$ sensor response with filter upon exposure to 5, 10 and $20 \mathrm{ppb}$ of isoprene at $90 \% \mathrm{RH}$. These ultra-low but breath-relevant concentrations are detectable, reproducible and clearly distinguishable (signal-to-noise ratio $>90$ ). The filter quickly and fully regenerates after each pulse. (b) Sensor response curves without (red circles) and with filter (blue crosses) over the entire breath-relevant concentration range of isoprene from 5 to $500 \mathrm{ppb}$ at $90 \% \mathrm{RH}$.

(show single column) 


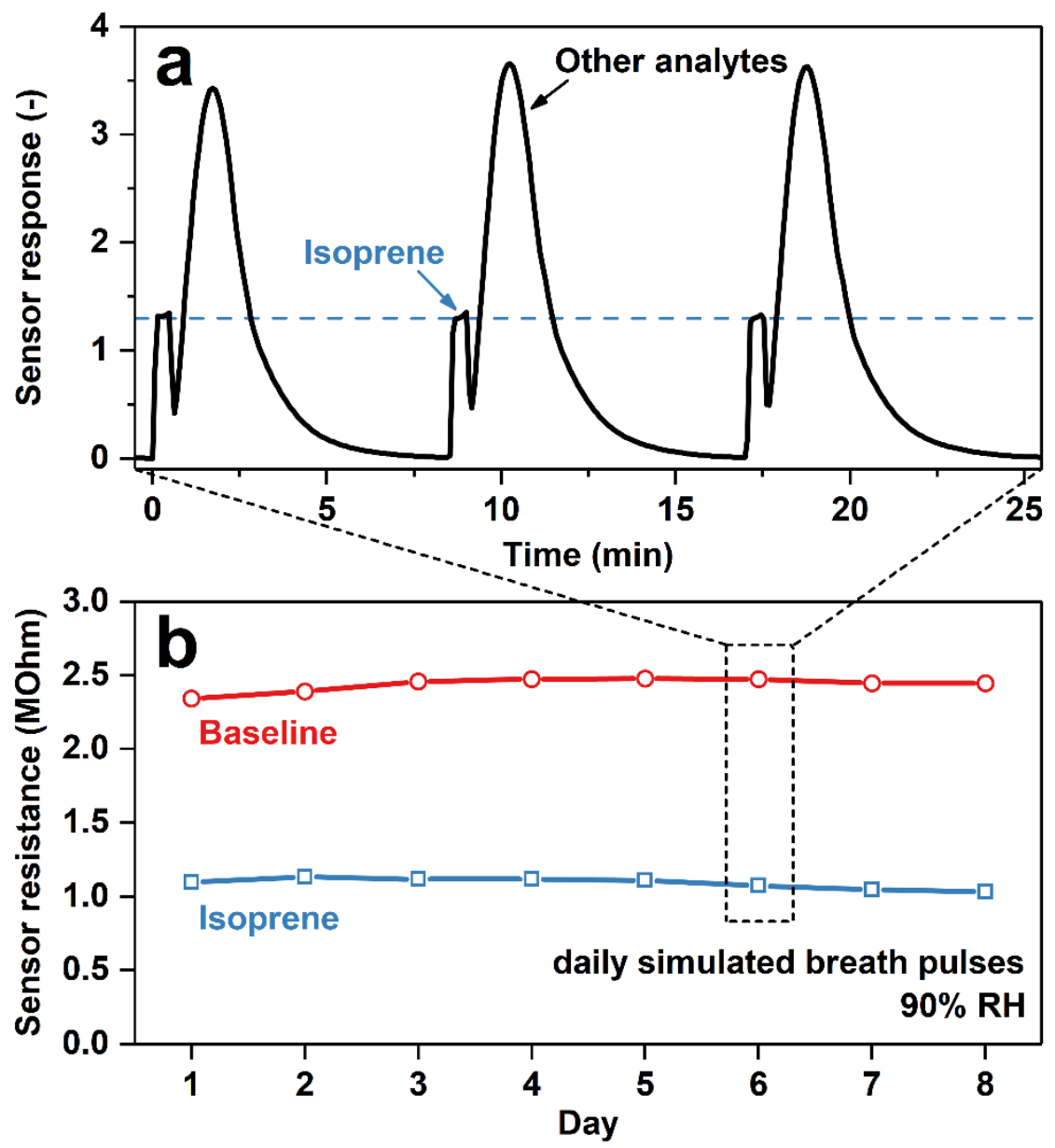

Figure 6. (a) Response of Pt-doped $\mathrm{SnO}_{2}$ with filter to three consecutive $30 \mathrm{~s}$ pulses of simulated breath composed of $106 \mathrm{ppb}$ isoprene, $477 \mathrm{ppb}$ acetone, $461 \mathrm{ppb}$ methanol and $833 \mathrm{ppb}$ ammonia at $90 \% \mathrm{RH}$ on the sixth day of continuous monitoring. (b) Evolution of the sensor baseline resistance (red circles) and the isoprene response resistance (blue squares) during eight days of continuous operation and daily simulated breath analysis. (show single column) 
For TOC only

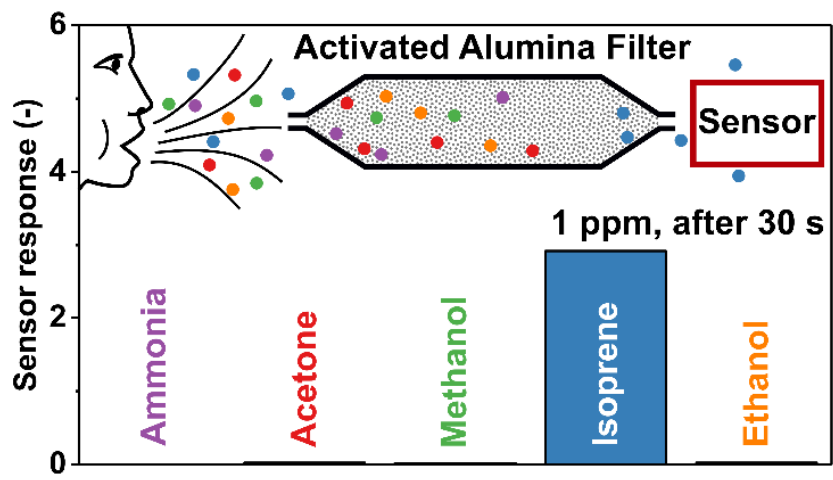

